УДК 343.771

DOI: 10.21209/1996-7853-2020-15-6-72-80

Денис Николаевич Беспалько, Забайкальский государственный университет (2. Чuma, Россия), e-mail: bespalkodenis84@mail.ru, https://orcid.org/0000-0001-8957-0410

\author{
Нормативно-правовые акты Дальневосточной республики (1920-1922), \\ регулирующие правила охотничье-промысловой деятельности населения
}

Статья посвящена изучению истории развития нормативно-правовых актов охотничье-промыслового законодательства Дальневосточной республики. Рассмотрены основополагающие положения и уставы, издаваемые министерствами земледелия и народного нозяйства: «Положение о производстве охоты», «Краткий временный устав организации промысловых охотничье-рыбных артелей и обществ» и «Проект временного устава организации народных охотничьих и рыболовных обществ правильной охоты». Применены историко-генетический, историко-сравнительный, конкретно-исторический и формально-юридический методы научного познания, с помощью которых анализируются проблемы определения промысловых и непромысловых районов, использования разрешённых и запрещённых способов охоты, сроки действия промыслового сезона и причины введения некоторых ограничений. Рассматриваются развитие дореволюционной практики выборки государственного билета, разрешающего право на охоту; регулирование деятельности кооперативных сообществ охотников и экспериментальная система наказания, предусматривавшая не только административную, но и уголовную ответственность за нарушение правил охоты и браконьерство. Значительная часть нововведений воспринималась гражданами республики как посягательство на личные права, поскольку по традиции все промысловые ресурсы на территории Сибири и далее на Восток вплоть до 1917 г. добывались без каких-либо серьёзных ограничений и контроля со стороны государства. Прежнее положение дел в рассматриваемый период времени сохранялось исключительно для тех групп населения, что целиком зависели от продуктов охоты и рыболовства. Все остальные социальные категории ДВР были обязаны соблюдать новые правила, вставать на учёт и выплачивать налог за право использования государственно-промысловой регалии. Эффективность вводимых мер оставляла желать лучшего, поскольку органы контроля не имели реальной возможности действенного пресечения нарушения промыслового законодательства.

Ключевые слова: Дальневосточная республика, устав, проект, право производства охоты, охотничий билет, браконьерство, мера наказания

Denis N. Bespal'ko, Transbaikal State University (Chita, Russia), e-mail: bespalkodenis84@mail.ru, https://orcid.org/0000-0001-8957-0410

\title{
Normative Legal Acts of the Far Eastern Republic (1920-1922) Regulating the Rules of Hunting and Fishing Activities of the Population
}

The article is devoted to the study of the history of the development of regulatory legal acts of hunting and hunting legislation of the Far Eastern Republic. The basic provisions and statutes issued by the Ministries of Agriculture and National Economy are considered: "Regulations on the production of hunting", "Brief temporary charter for the organization of commercial hunting and fish artels and societies" and "Draft temporary charter for the organization of folk hunting and fishing societies of correct hunting". Historical-genetic, historical-comparative, concrete-historical and formal-legal methods of scientific cognition are applied. With their help, the problems of determining the fishing and non-commercial areas, the use of permitted and prohibited hunting methods, the duration of the fishing season and the reasons for the introduction of certain restrictions are analyzed. Further, the author examines the development of the pre-revolutionary practice of sampling a state ticket allowing the right to hunt, regulation of the activities of cooperative communities of hunters and an experimental system of punishment, which provided not only administrative but also criminal liability for violation of hunting rules and poaching. A significant part of the innovations was perceived by the citizens of the republic as an encroachment on personal rights, since, by tradition, all commercial resources in Siberia and the East were mined without any serious restrictions and control from the state until 1917. The previous state of affairs during the period under review remained exclusively for those groups of the population that were entirely dependent on hunting and fishing products. All other social categories of the Far Eastern Republic were required to comply with the new rules, 
register and pay tax for the right to use the state-fishing regalia. The effectiveness of the measures introduced left much to be desired, since the control bodies did not have a real opportunity to effectively suppress violations of the fishing legislation.

Keywords: Far Eastern Republic, charter, draft, hunting license, hunting ticket, poaching, punishment

Введение. В 1920-1922 гг. на территории Забайкалья и Дальнего Востока было образовано буферное государство - Дальневосточная республика (ДВР) с центром в г. Чите [7, с. 70]. С первых дней своего существования республиканские органы власти активно занимались разнообразной законотворческой деятельностью [1], в частности издавали нормативно-правовые акты, направленные на охрану охотничье-промысловых и рыбных ресурсов, борьбу с браконьерством, нарушениями общих правил заготовки пушно-мехового сырья [13, с. 251].

В Основном законе ДВР, Конституции 1921 г. статьями 126 и 127 леса, воды и их богатства объявлялись государственной собственностью и достоянием всего народа ${ }^{1}$. Априори это означало лишь то, что все промысловые ресурсы объявлялись государственным достоянием, на которое не имели частных прав отдельные граждане или юридические лица. Подавляющее же большинство промысловиков, без проведения разъяснительной работы соответствующих органов исполнительной власти, восприняли подобные изменения исключительно в удобной для себя форме - возможности личного и неподконтрольного государству распоряжения дарами природы (данное положение дел имеем возможность повсеместно наблюдать на изучаемой территории республики до её образования) [6]. Благодаря этому, у населения, так или иначе принадлежащего к охотничье-промысловой среде, продолжала развиваться порочная практика хищнического отношения к промысловым ресурсам. В республике, по ложному пониманию гуманизма, в угоду давно изжитой, не отвечающей условиям времени традиции, государственные домены беспощадно расхищались. Массовое исчезновение пушных зверей и дичи происходило вследствие нерациональной и бесконтрольной эксплуатации охотничье-промысловых угодий. Наметившаяся до 1917 г. тенденция к снижению доходов от пушного промысла в начале 1920-х гг. стала явлением постоянным².

Н. В. Эйльбарт обратила внимание, что в доставшейся по наследству дореволюци-

${ }^{1}$ Дальневосточная республика. Основной закон (Конституция) 27 апреля 1921 г. - Чита: Гос. тип. № 1 , 1921. - С. 11.

2 Государственный архив Забайкальского края. ГАЗК. - Ф. Р-441. - Оп. 1. - Д. 2. - Л. 50. онной нормативно-правовой базе не уделялось серьёзного внимания охране дикой фауны и пресечению незаконной деятельности браконьеров [15]. Такие законодательные акты как «Свод правил об охоте» (1882), «Первый Охотничий закон» (1892) и некоторые другие, по мнению заведующего хозяйством Императорской охоты Н. И. Кутепова, не соответствовали или мало соответствовали новым реалиям времени уже в начале XX в. [8]. Требовалась выработка более совершенного законодательства. Поэтому правительство ДВР с апреля 1920 г. проводило активную политику по ужесточению правил охоты и разработало экспериментальную систему наказания за их нарушение. Под руководством заведующего Иркутско-Забайкальским охотничьим районом и автора научно-литературного труда «Проект Всероссийского закона об охоте» ${ }^{3}$ Н. А. Михайловского Министерством земледелия и народного хозяйства был создан ряд документов, строго обязательных для исполнения всеми членами охотничье-промыслового контингента республики: «Положение о производстве охоты», «Краткий временный устав организации промысловых охотничье-рыбных артелей и обществ» и «Проект временного устава организации народных охотничьих и рыболовных обществ правильной охоты». Главным образом, их разработка была направлена на создание правил по организации рационального охотничьего хозяйства в государственном масштабе, на упорядочение местных охотничьих промыслов, повышение уровня их доходности и на охрану дичи от хищнического истребления. Новые правила организации промысловой деятельности органично дополняли друг друга и, в конечном итоге, должны были помочь сформировать образцовый тип охотничьего хозяйства, близкий к западноевропейскому аналогу. Именно на него идейно и ориентировались при написании проектов. В объяснительной записке к министерствам Н. А. Михайловский отмечал, «...что только в России охота считается забавою доступной всем. Запад ничего подобного не знает. Германия ведёт правильное, интенсивное охотничье хозяйство. Англия образцово охраняет свои африканские охотничьи угодья,

3 Проект не был поддержан правительством ДВР, но его положения косвенно повлияли на выработку новых правил об охоте. 
извлекая из них огромный доход. Америка, растратившая, подобно нам, свои охотничьи запасы, со свойственной ей решимостью, взялась за их упорядочение, не останавливаясь перед полным запрещением охоты в различных частях Штатов, и образованием огромных заповедников. В остальных странах также строго и внимательно относятся к интересам охотничьего хозяйства и везде на западе осуществление права охоты сопряжено с несением крупных расходов, не всем доступных...»¹. Заключительная часть данного отрывка свидетельствует о том, что вектор промыслового законотворчества уже на ранних стадиях подготовки начинал приходить в изрядное противоречие с образом жизни значительной части русских крестьян и коренного населения, поскольку изначально предполагалось распространить действие новых правил на всю территорию ДВР. Принятие и узаконивание подобного рода положений в условиях рассматриваемого времени, без учёта мнения широкой общественности охотников, могло привести лишь к единственно возможному сценарию - массовому неповиновению и усилению браконьерства. Что, к примеру, и доказала недальновидная сырьевая политика правительства, направленная на монополизацию сфер заготовок, хранения и торговли пушниной и сырьём [3]. Поэтому вплоть до упразднения государственной самостоятельности ДВР, в ноябре 1922 г. промысловое законодательство, подразумевая в теоретическом плане западный вариант закона и в перспективе проведение соответствующей реформы, всё же было вынуждено отчасти следовать дореволюционным нормативно-правовым традициям [2; 5], существенно не ущемляя ничьих интересов на территории дальневосточной республики².

Методология и методы исследования. Изучение темы проводилось в соответствии с основными принципами исторического исследования, принципами объективности и историзма. Исходя из этих принципов, в статье определён и использован ряд методов научного познания: историко-генетический - с его помощью последовательно раскрыты положения и изменения нормативно-правовых актов промыслового законодательства ДВР в процессе их применения; историко-сравнительный метод позволил выявить преемственную основу и различия между дореволюционными правилами и законами об охоте с республиканскими; с помощью конкретно-исторического ме-

\footnotetext{
${ }^{1}$ ГАЗК. - Ф. Р-441. - Оп. 1. - Д. 1. - Л. 8 об.-9.

2 Там же. - Ф. Р-18. - Оп. 1. - Д. 72. - Л. 19-19 об.
}

тода изучена специфика охотничье-промыслового законодательства в хронологических рамках существования ДВР как отдельного от РСФСР государства; формально-юридический метод находится в основе систематизации малоизученного промыслового законодательства ДВР. Проанализированы акты промыслового законодательства, изданные до 1917 года; ведомственные материалы Иркутско-Забайкальского охотничьего района, в частности Забайкальского отдела Всероссийского общества правильной охоты и Управления по делам рыболовства и охоты, Центрального народного государственного контроля (Госконтроль), Министерства земледелия и народного хозяйства 1920 1922 годов; специализированная научная и справочная литература.

Результаты исследования и их обсуждение. Первый нормативно-правовой акт ДВР «Положение о производстве охоты» ${ }^{3}$ (далее - «Положение»), его параграф 5 предельно чётко устанавливал, что охота как основной способ добычи мясных продуктов питания и пушнины, разрешается только в промысловых районах, преимущественно местах компактного проживания или кочевья «звероловнического и инородческого населения». Все остальные территории считались непромысловыми и предполагали производство добычи только в качестве источника подсобных заработков. Разделение на районы осуществлялось областными органами Управления рыболовства и охоты [9].

Охота как вид деятельности подразделялась на спортивную (любительскую и егерскую, производимую с научными или иными целями) и промысловую. Определялись законные методы добывания зверей: ружейная охота с собакой, с использованием самоловного оборудования. Запрещались способы, признанные негуманными по отношению к дикой природе и являющиеся условно наказуемыми ещё в дореволюционное время. К таким относилось применение настороженных ружей, самострелов, разного рода городьбы и устройства ям. Настороженные ружья и самострелы, изначально применяемые тунгусами, были одинаково опасны как для животных, так и для человека. Промысловые ямы, используемые чаще всего русскими охотниками, вели к очень быстрому истреблению копытных на размещаемой территории, поэтому ещё в 1893 г. царским указом отлов изюбрей и лосей с их помощью в Забайкалье и на Дальнем Востоке был полностью запрещён. Данный метод 
добычи считался гуманным, но за 7-8 лет, как отмечал в конце XIX в. А. К. Кузнецов, приводил к полному уничтожению крупных зверей в промысловой местности, т. к. на

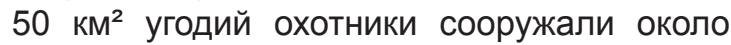
100 ямных ловушек, куда попадали все без исключения парнокопытные [14, с. 125, 126].

Использование ядохимикатов, в частности стрихнина, разрешалось только в исключительных случаях, при борьбе с хищниками, наносящих значительный вред сельскому хозяйству. Для его приобретения требовалось прохождение специальной процедуры получения именного разрешения по ходатайству сельского общества или охотничьей организации, в которой состоял сезонный охотник или профессиональный промысловик. В противном случае, применение стрихнина на территории промысла считалось незаконным. Запрещалась и неподконтрольная государственным органам торговля ядохимикатом. Незаконная продажа/покупка и использование стрихнина приравнивались к уголовно наказуемым деяниям. В качестве наказания предполагалось применять меру пресечения свободы сроком на 1-3 месяца без замены денежным штрафом ${ }^{1}$.

В отношении владения и использования огнестрельного оружия налагались определённые ограничения. Так, в параграфе 10 указывалось, что владение оружием допустимо только лицам, имеющим охотничий билет ${ }^{2}$. Торговля охотничьими боеприпасами (порох, дробь и пистоны) осуществлялась согласно параграфу 26, по которому оптовая торговля разрешалась на общих основаниях, розничная - при наличии охотничьего билета. Нарушение правил торговли каралось тюремным заключением на срок 1-3 месяца без замены денежным штрафом ${ }^{3}$.

Достаточно жёстко регулировались основные и второстепенные сроки охотничье-промыслового сезона. Охота разрешалась только в установленное время, с конца августа и до середины мая. С 15 мая и до 15 августа (по новому стилю) всяческое добывание зверей и пернатой дичи запрещалось. В порядке исключения стояла лишь узкоспециальная и высокодоходная отрасль заготовка изюбриных пантов, производящаяся в сроки, устанавливаемые областными органами Управления рыболовства и охоты (главным образом, весенне-летняя охота за изюбрем осуществлялась с 15 мая по

\footnotetext{
${ }^{1}$ ГАЗК. - Ф. Р-585. - Оп. 1. - Д. 3. - Л. 20 об.

2 Там же. - Л. 21 об.

${ }^{3}$ Там же. - Л. 23 об.
}

1 июля). Нарушение сроков охоты каралось лишением свободы на срок от 3 до 6 месяцев или денежным штрафом от 25 до 50 р. золотом ${ }^{4}$. Данная статья не распространялась на таёжные поселения, где население круглый год жило продуктами охоты. В изменившихся после 1917 г. условиях принятие решения об ограничении сроков охоты преследовало ряд важных задач: 1) изживание представлений об охоте как «божьем даре», доступном в любое время года каждому желающему; 2) охрана подрастающего молодняка и дикой фауны в период размножения; 3) становление практики наблюдения лесными и егерскими службами за производством охоты, ведения статистики, задержания нарушителей и т. д.

Установление относительно точных сроков охоты проходило в обстановке бурных общественных дебатов, т. к. на занимаемой ДВР территории действовал древний «закон тайги», по которому охотник или промысловая артель/бригада ориентировались не только на сезонность промысла как такового, но и его целесообразность. В летний период времени не имело смысла заготавливание пушно-меховой продукции, но для пропитания, разрешалось добывать необходимое количество дичи. В противном случае требовалось решить продовольственную проблему и вопрос возможных путей снабжения охотников в тайге во время проведения подготовительных работ и предпромысловой разведки. Необходимо отметить, что организованный завоз продуктов питания, охотбоеприпасов и других необходимых на промысле вещей стал регулярным объектом заботы государства только в 1930-е гг., после реализации политики коллективизации.

«Положение» развивало дореволюционную практику использования охотничьих билетов, разрешающих право на охоту. Производство охоты и владение огнестрельным оружием допускалось на основании Конституции ДВР только лицам, выбравшим правительственный охотничий билет в учреждениях Управления рыболовства и охоты. При этом для коренных народов делалась скидка, чтобы платное пользование охотой резко не нарушало их интересы. По особому, в каждом отдельном случае постановлению министра народного хозяйства могла быть разрешена охота по бесплатным билетам. Билет мог получить гражданин ДВР с 17 лет, уплатив специальный налог, за исключением лиц осуждённых судом за нарушение охотничьих правил и ранее со- 
вершивших уголовные преступления. Сроки ограничения, в зависимости от квалификации административного или уголовного дела, были различны: от 5-10 лет до пожизненного. Но по решению суда ограничение в правах охоты могло быть сокращено до трёх лет ${ }^{1}$. Несовершеннолетние граждане ДВР могли получить билет только по письменному ходатайству родителей или опекунов. В непромысловых районах сельские жители обязаны были иметь билет на каждого охотника, без права его передачи другому члену семьи. В случае нарушения правила проступок рассматривался и карался как подлог. В промысловых районах, где охота являлась основным средством существования, билет выбирался на главу семьи с правом его передачи другим членам. Но данное право оплачивалось высшей ставкой налога. Срок ежегодного получения охотничьего билета начинался 1 января и заканчивался 1 апреля. По истечении данного срока на билет начислялась пеня за просрочку в размере 1/2 стоимости билета за каждые две недели просрочки. В случае обнаружения безбилетной охоты с виновного взыскивалась тройная стоимость билета².

Как видим, меры наказания не предусматривали серьёзных ограничений для преступивших закон. Однако в крайних случаях полагалось более суровая «кара». Параграфф 19 «Положения» предусматривало высшую меру наказания от 3 до 6 месяцев лишения свободы без замены денежным штрафом. Его применяли в случаях квалификации следующих преступлений: 1) хищническое истребление ценных, малочисленных и быстроисчезающих зверей (особо оговаривался запрет на охоту в случае полной беспомощности копытных - при переправах через реки и по насту); 2) массовое истребление пернатой дичи в зимний период времени сетями, силками и прочими самоловами; 3) разорение гнёзд, истребление молодняка; 4) торговля запретной дичью и в запретное время; 5) жестокое обращение с дикими и домашними животными ${ }^{3}$. Ловля диких животных и птиц в целях содержания в неволе как объектов звероводства и птицеводства разрешалась так же в строго установленные для охоты сроки. Нарушение данного правила квалифицировалось как уголовное преступление и каралось аналогичным сроком лишения свободы на основании названного параграфра.

После окончания сезона промысловой охоты запрещалась торговля любой дичью.

\footnotetext{
${ }^{1}$ ГАЗК. - Ф. Р-585. - Оп. 1. - Д. 3. - Л. 21 об.

2 Там же. - Л. 22.

${ }^{3}$ Там же. - Л. 22 об.-23.
}

В случае обнаружения данного фракта правоохранительные органы имели право привлечения к ответственности как торговца, так и покупателя. Интересными являются положения пунктов 1-4 параграфа 23 о полном запрете торговли: дичью давленой петлями; мелкой, линяющей птицей и птенцами; неспелой пушниной и шкурками особей, не достигших зрелого возраста. Причины подобного запрета общество видело, прежде всего, в попытке государства навязать свои правила, но объективное оценивание сложившейся ситуации заставляет по-другому взглянуть на запретительные меры. Разного рода удавливающие снасти были запрещены как негуманные и расточительные по отношению к промысловым ресурсам, соответственно, и торговать добытой с их помощью дичью являлось делом незаконным. В отношении категорий линяющей птицы (неспелой пушнины) и истребления молодняка, которые подчас добывались ради лёгкой наживы, необходимо также подчеркнуть правильность принятого решения. В противном случае, видовое разнообразие промысловых угодий ждала участь соболя, практически истреблённого в большинстве районов республики ещё в начале $\mathrm{XX}$ в.

Для предотвращения случаев браконьерства и последующей незаконной торговли дичью и пушниной вводился ряд ограничений. Согласно параграфу 25 «Положения» и Торговому закону от 3 октября 1922 г., скупка и торговля пушниной запрещалась: 1) при отсутствии у профессионального торговца лицензионного свидетельства; 2) при отсутствии у продавца-промышленника охотничьего билета; 3) в случае передачи охотничьего билета с целью сбыта продукции другому лицу4 ${ }^{4}$ Нарушение правил торговли каралось лишением свободы на срок от трёх месяцев, без замены денежным штрафом.

Для стимулирования населения на борьбу с браконьерами и нарушителями вводилось специальное поощрение. В случае сообщения достоверных сведений об имевшемся случае правонарушения информатор получал по решению суда 2/3 суммы, выручаемой от конфискации незаконной добычи, орудий лова и суммы гражданского иска, предъявляемого истцом виновному.

К сожалению, перечисленные меры наказания, как в прочем и значительная часть последующих за ними, подавляющим большинством знатоков охотничьего дела воспринимались сначала с негодованием, а затем с осознанием неспособности власти

${ }^{4}$ Там же. - Л. 23 об. 
контролировать собственные постановления, и не были приняты к вниманию. Карательная система республики находилась в удручающем состоянии. Разъездные агенты, как показывают исследования, спокойно скупали у населения все сорта пушнины и мясодичной продукции без проверки документов, удостоверяющих право производства охоты, размещали на складах хранения и затем производили реализацию на внутреннем и внешнем рынках $[11 ; 12]$.

Следующим шагом стала разработка и опубликование проекта, направленного на создание регулярно фрункционирующих первичных объединений промысловиков [10, c.68], чтобы на данной основе в дальнейшем организовать полноценный промысловый союз общегосударственного значения «Краткий временный устав организации промысловых охотничье-рыбных артелей и обществ» (далее - «Устав»)1. После его принятия общества охотников заговорили о нарушении свободы личности, содержащейся в параграфе $1^{2}$, где по существу, лишь говорилось о получении официального разрешения на производство добычи промысловой дичи/ рыбы в составе артели и разумного отношения к их быстро сокращающимся запасам. Но с точки зрения рядового обывателя, не было основания ограничивать право охоты требованием принадлежности к организованной охотничьей корпорации; право это, по мнению обывателя, должно было по старинке принадлежать всем без ограничений и правовых изъятий. Если же немного углубиться в суть проблемы, то мы убедимся, что время создания профессионально-промысловых объединений, осуществляющих разработку промысловых ресурсов на основе единых правил, назрело. С 1872 г., времени организации Первого московского общества правильной охоты, образовавшиеся в регионах охотничьи организации не сумели поставить перед собой государственных задач, не соблюдали интересов промысла и преследовали только свои узкоспециальные интересы. Их главными недостатками являлись, с одной стороны, привилегированность состава, а с другой, отсутствие центрального руководящего органа. Именно это и не позволяло образоваться единому промысловому союзу. Исходя из этого, требовалось проведение следующих мероприятий: 1) уменьшение числа охотников за счёт исключения случайного элемента, т. к. последние в крайне незначительном числе желали или могли

\footnotetext{
1 ГАЗК. - Ф. Р-441. - Оп. 1. - Д. 1. - Л. 1-3 об.

2 Там же. - Л. 10.
}

себе позволить официально оплачивать хозяйственно-корпоративные расходы (именно таким путём осуществлялась наиболее безболезненная ликвидация целой «армии» непрофессиональных любителей охоты); 2) корпоративные интересы ограничивали хищничество своих членов, постепенно исключая из своей среды откровенных вредителей (эта мера подразумевала возможность уравновешивания количества дичи с числом действительных зверопромышленников, зависящих от размера добычи); 3) корпоративная организация позволяла объединить разрозненные группы промысловиков, не поддающихся ни учёту, ни контролю в лиц юридических; 4) ввести планомерную регистрацию оружия. На основании закона от 3 мая 1922 г. и инструкции Министерства народного хозяйства от 4 июля 1922 г., охотничий билет являлся единственным документом, на основании которого разрешалось владеть и пользоваться на охоте оружием не только охотничьего, но и военного образца ${ }^{3}$. Соответственно, никакого ущемления прав не произошло. Государство-собственник имело полное право предоставлять пользование своими регалиями на определённых условиях, нежелающие их соблюдать тем самым добровольно отказывались от пользования. Каждая сторона была самостоятельна в своём решении. Если в «Уставе» и имелась доля принуждения, то она проходила красной нитью в государственно-хозяйственном распорядке торговли, промышленности и так далее, всё подчинялось той или иной регламентации. Общественность ДВР поступала точно так же, утилизируя те или иные формы профессиональной или партийной дисциплины. Даже в глубинах тайги существовала неписаная строгая регламентация личных поступков. Если не по закону Линча 4 , то получением пули от неизвестных судей. В особенности это касалось нарушения таёжного закона.

«Устав» значительно расширял правоохранительную базу и предлагал реальный выход из прочно установившегося круга инертности, хищничества и уклонения от соблюдения Закона. Права должны были сочетаться с обязанностями, без которых невозможно сформировать цивилизованное отношение к промысловым ресурсам. Поэтому разделом 5 параграфа 10 устанавлива-

${ }^{3}$ Там же. - Л. 2.

4 Закон, или суд Линча - высшая мера наказания для человека, подозреваемого в совершении преступления. Смертный приговор, как правило, выносился гражданским населением без проведения следственных мероприятий и судебных разбирательств. 
лись требования и необходимый правительственный контроль, при котором возможные уклонения с профессионально-технической дороги могли быть пресечены в самом начале. Промысловые артели были обязаны соблюдать все законы и правила по рыболовству и охоте, организовывать промысловую охрану зверя, птицы и наблюдение за торговлей продуктами промыслов через особо уполномоченных членов. За нарушение правил и законов предоставлялось право временно лишать участия в общественных охотах, в пользовании учреждениями общества охотников или исключать из корпорации путём голосования $2 / 3$ её членов ${ }^{1}$.

В его основе также находилась попытка решения наиболее спорных вопросов, незатронутых «Положением». «Устав» предлагал решить проблему «балующихся ружьём», называя причастных к забаве лиц «величайшей язвой охотничьего хозяйства, лесными хулиганами». Действительно, последние не принадлежали к промышленникам или спортсменам, были незнакомы с охотничьей этикой и лишены даже примитивного понимания смысла охоты. В качестве решения предполагалось запретить «праздничным палилам» вообще находиться на территории формирующихся охотничье-промысловых хозяйств.

В отношении коренных этносов положения «Устава» сохраняли мудрый принцип: «Каждое мероприятие целесообразно постольку, поскольку оно практически осуществимо». Его действие, таким образом, не распространялось на глухие и таёжные промысловые районы с кочующим и бродячим инородческим населением, поскольку вводимые нормы не соответствовали традиционному укладу их жизни [4]. Артельные начала, как неоднократно отмечал В. В. Сонин, хотя и являлись неотъемлемой составляющей социальной структуры большинства малых этнических групп раннеклассовых обществ, тем не менее, с правовой точки зрения противоречили нормам товарно-рыночных отношений [13].

Последним, в августе 1922 г. выходит «Проект временного устава организации народных охотничьих и рыболовных обществ правильной охоты» ${ }^{2}$ (далее - «Проект»), дополняющий предыдущие акты. Для пресечения массового использования на незаконной охоте нелегально приобретённого оружия в разделе 1, параграфа 4 пункта 2 и параграф 5 пункт 2, его разрешалось иметь

\footnotetext{
1 ГАЗК. - Ф. Р-441. - Оп. 1. - Д. 1. - Л. 2 об.

2 Там же. - Л. 27-31 об.
}

и эксплуатировать преимущественно лицам промысловым, состоящим в профессиональных обществах. Вводимый ряд новых понятий - «владение огнестрельным оружием» и «содержание огнестрельного оружия» и их определение, подчёркивали ограничения для остальных гражданских лиц 3 . Данная норма вызвала очередной протест, поскольку уже в рядах Госконтроля справедливо полагали, что она отразится тяжким бременем на части русских крестьян и инородцев, проживающих исключительно в условиях таёжной местности и питающихся значительную часть года продуктами рыбохоты. Потребовалось внесение специальной поправки, допускающей частичную возможность исключения применения ограничивающих нормативно-правовых понятий из процессуального оборота. Стоит оговориться, что подлинный текст поправки не обнаружен, но косвенно на её возможное существование указывает обращение Министерства по национальным делам к туземцам ДВР в августе 1922 года [7, с. 123]. При этом, в «Проекте» недостаточно чётко разграничивалось применение определённых норм в конкретных случаях. В разделе 3 параграфа 2 пункта 6 предусматривалась «конфискация» оружия и незаконной добычи, в случае обнаружения правонарушения 4 . Но представители Госконтроля настаивали на использовании термина «отобрания», т. к. милиция и иные правоохранительные органы правом конфискации не обладали. Право конфискации могло осуществляться только по приговору суда или в силу особого закона. В остальном «Проект» копировал положения предыдущего «Устава».

Разработка, обсуждение и принятие рассмотренных нормативно-правовых актов осуществлялись в обстановке военного времени и хозяйственной разрухи. Чрезвычайные обстоятельства требовали решительных действий, но катастрофически не хватало времени на апробацию и сглаживание юридических шероховатостей. Органы исполнительной власти ДВР часто не могли прийти к единому мнению по поводу вводимых нововведений. Госконтроль большую часть предоставляемых на рассмотрение проектов одобрял, за исключением названного «Положения», чего нельзя сказать о юрисконсультской части Министерства народного хозяйства 5 . В своём заключении Министерство последовательно придерживалось линии соответствия норм конститу-

\footnotetext{
${ }^{3}$ Там же. - Л. 27 об.

${ }^{4}$ Там же. - Л. 29.

${ }^{5}$ ГАЗК. - Ф. Р-409. - Оп. 1. - Д. 3.
} 
ционного права с предлагаемыми нормативно-правовыми изменениями. Все проекты, по его мнению, противоречили основному закону в части соблюдения личных прав и гражданских свобод населения и нуждались в кардинальной переработке ${ }^{1}$.

Заключение. В заключение необходимо отметить степень эффеективности нового законодательства. Надзор за соблюдением охотничьих правил возлагался на городскую и сельскую милицию, лесную, полевую и промысловую стражу, сельские и волостные органы управления, уполномоченных членов охотничьих организаций, лесничих и их помощников. Но реальных сил для борьбы с нарушителями правил охоты и браконьерами республика не имела. С одной стороны, не хватало личного состава во всех ранее перечисленных структурных подразделениях правопорядка. С другой, трудность разрешения охотничьего вопроса в ДВР обусловливалась особым взглядом населения на естественные произведения природы - лес, зверей и птиц как на «божий дар», доступный пользованию каждого желающего. Упорядочивая охоту, приходилось идти в разрез с мировоззрением коренной массы населения, что и являлось главной из причин непопулярности действующих правил охоты: охотники и чины надзора за исполнением законов об охоте, администрации и судебного ведом- ства зачастую бывали склонны отступать от правил, и сами нарушали закон. Между тем, переход от вольной охоты в виде безучётного пользования дичью как даровой продукцией к организации правильного охотничьего хозяйства, где дичь является объектом хозяйственных забот, известного рода ценностью - как продукт затраты труда и капитала - был жизненно необходим.

Роль республиканских законов в сохранении запасов дичи и правильной постановке охоты оказалась далеко не столь безусловна, как это может показаться при знакомстве с первоисточниками. Закон об охоте является внешним регулятором, несколько нормирующим пользование ресурсами живой природы. Для правильной же постановки охотничьего дела был необходим внутренний импульс со стороны охотников к охране дичи. Никакой, даже самый идеальный закон не в силах предотвратить истребление промысловой фауны в законное время дозволенными способами, раз у самих охотников нет желания её охранять. Импульсом же к охране дичи может быть главным образом только сознание получаемой от этого выгоды. Поэтому, со временем на более высоком уровне в недрах Управления по делам рыболовства и охоты предполагалось заняться хозяйственно-финансовой стороной дела - привить населению рационально-экономический взгляд на охоту.

\section{Список литературы}

1. Авдеева Н. А. Дальневосточная народная республика (1920-1922 гг.). Хабаровск: Хаб. кн. изд-во, 1957.64 с

2. Бабай А. Н. Государственно-правовое развитие ДВР: исторический опыт, современность, перспективы. Владивосток: Изд-во ДВГУ, 1983. 196 с.

3. Беспалько Д. Н. Особенности развития пушно-сырьевого сектора экономики на территории Забайкалья в период существования Дальневосточной Республики (1920-1922) // Историко-экономические исследования. 2019. № 4. С. 640-664.

4. Беспалько Д. Н. Проблемы регулирования традиционных основ охотничьего промысла малых народов Забайкалья в 1920-1922 гг. // Укрепление единства российской нации и этнокультурное развитие народов Забайкалья: сб. ст. Междунар. науч.-практ. конф. (16 мая 2019 г.). Чита: ЗабГУ, 2019. С. 116-118. $144 \mathrm{C}$.

5. Василевский В. И. Борьба за Советскую власть в Забайкалье. Иркутск: Вост.-Сиб. кн. изд-во, 1979.

6. Егунов П. П. Очерки истории Дальневосточной республики. Улан-Удэ: Бур. кн. изд-во, 1972. 116 с.

7. Константинов А. В., Константинова Н. Н. Забайкалье: ступени истории (1917-1922 годы). Чита: Экспресс-издательство, 2009. 192 с.

8. Кутепов Н. И. Императорская охота на Руси. Т. 4. Конец XVIII и XIX век. СПб.: Экспедиция изготовления госбумаг, 1911. 289 с.

9. Левкин Г. Г. Образование и административно-территориальное устройство Дальневосточной Республики. Хабаровск: [б. и.], 2018. 441 с.

10. Мерцалов В. И. Забайкалье в контексте российской истории (середина XVII - начало XXI в.). Чита: ЗабГУ, 2019. 158 с.

11. Персиц М. А. Дальневосточная республика и Китай. М.: Изд-во вост. лит., 1962. 304 с.

12. Попенко А. В. Борьба с контрабандой на Дальнем Востоке России в первые годы советской власти и в период ДВР // Проблемы Дальнего Востока. 2009. № 3. С. 50-59.

13. Сонин В. В. Государство и право ДВР. Владивосток: Дальнаука, 2011. 296 с.

${ }_{1}^{1}$ ГАЗК. - Ф. Р-616. - Оп. 1. - Д. 2. 
14. Самойлов Е. Б. Записки охотоведа. Чита: Поиск, 2004. Кн. 2. 295 с.

15. Эйльбарт Н. В. Исследования по охотоведению и звероводству в Забайкалье во второй половине XIX - начале XX века // Вестник Иркутского государственного технического университета. 2005 . № 4. C. 187-191

Статья поступила в редакцию 28.07.2020; принята к публикации 11.09.2020

\section{Сведения об авторе}

Беспалько Денис Николаевич, кандидат исторических наук, доцент, Забайкальский государственный университет; 672039, Россия, г. Чита, ул. Александро-Заводская, 30; e-mail: bespalkodenis84@mail.ru; https://orcid.org/0000-0001-8957-0410.

\section{Библиографическое описание статьи}

Беспалько Д. Н. Нормативно-правовые акты Дальневосточной республики (1920-1922) регулирующие правила охотничье-промысловой деятельности населения // Гуманитарный вектор. 2020.Т. 15, № 6. C. 72-80. DOI: 10.21209/1996-7853-2020-15-6-72-80.

\section{References}

1. Avdeeva, N. A. Far Eastern People's Republic (1920-1922). Khabarovsk: Khabarovsk book publishing house, 1957. (In Rus.)

2. Babay, A. N. State-legal development of the ER: historical experience, modernity, prospects. Vladivostok: publishing house of far Eastern State University, 1983. (In Rus.)

3. Bespal'ko, D. N. Features of the development of the fur and raw materials sector of the economy on the territory of Transbaikalia during the existence of the far Eastern Republic (1920-1922). Historical and economic research, no. 4, pp. 640-664, 2019. (In Rus.)

4. Bespal'ko, D. N. Problems of regulation of traditional bases of hunting of small peoples of Transbaikalia in 1920-1922. International scientific and practical conference "Strengthening of unity of the Russian nation and ethno-cultural development of the peoples of Transbaikalia". Proceedings of the International Scientific and Practical Conference. Chita: 16 May 2019: 116-118. (In Rus.)

5. Vasilevsky, V. I. The Struggle for the Soviet power in Transbaikalia. Irkutsk: East-Siberian publishing house, 1979. (In Rus.)

6. Yegunov, P. P. Essays on the history of the Far Eastern Republic. Ulan-Ude: Buryat publishing house, 1972. (In Rus.)

7. Konstantinov, A. V., Konstantinova, N. N. Transbaikalia: stages of history (1917-1922). Chita: Express publishing house, 2009. (In Rus.)

8. Kutepov, N. I. Imperial hunting in Russia. The end of the XVIII and XIX century. Vol. 4. St. Petersburg: The expedition of the production of state papers, 1911. (In Rus.)

9. Levkin, G. G. Formation and administrative-territorial structure of the far Eastern Republic. Khabarovsk: 2018. (In Rus.)

10. Mertsalov, V. I. Zabaikalye in the context of Russian history (mid-XVII - early XXI century). Chita: ZabGU, 2019. (In Rus.)

11. Persits, M. A. Far Eastern Republic and China. Moscow: publishing house of the East. literature, 1962. (In Rus.)

12. Popenko, A. V. Fight against smuggling in the Far East of Russia in the first years of Soviet power and during the ER. Problems of the Far East, no. 3, pp. 50-59, 2009. (In Rus.)

13. Sonin, V. V. State and law of the Russian Federation. Vladivostok: Dalnauka, 2011. (In Rus.)

14. Samoylov, E. B. Notes of a hunter. Book 2. Chita: Search, 2004. (In Rus.)

15. Eilbart, N. V. Research on hunting and animal husbandry in Transbaikalia in the second half of the XIXearly XX century. Bulletin of Irkutsk state technical University, no. 4, pp. 187-191, 2005. (In Rus.)

Received: July 28, 2020; accepted for publication September 11, 2020

\section{Information about author}

Bespal'ko Denis N., Candidate of History, Associate Professor, Transbaikal State University; 30 AleksandroZavodskaya st., Chita, 672039, Russia; e-mail: bespalkodenis84@mail.ru; https://orcid.org/0000-0001-89570410

\section{Reference to the article}

Bespal'ko D. N. Normative Legal Acts of the Far Eastern Republic (1920-1922) Regulating the Rules of Hunting and Fishing Activities of the Population // Humanitarian Vector. 2020. Vol. 15, No. 6. PP. 72-80. DOI: 10.21209/1996-7853-2020-15-6-72-80. 